\title{
Connecting Microscopic Geological Features to Pore Geometry and Pore Structure: Case Study - Sandstone Reservoir of Balikpapan Formation, Kutai Basin
}

\author{
Junita Trivianty Musu $^{1}$, Pudji Permadi $^{1} \&$ Bambang Widarsono $^{2}$ \\ ${ }^{1}$ Petroleum Engineering, Faculty of Mining and Petroleum Engineering, Institut Teknologi Bandung, Indonesia \\ ${ }^{2}$ Research and Development Centre for Oil and Gas Technology "LEMIGAS, Jakarta, Indonesia \\ Correspondence: Junita Trivianty Musu, Petroleum Engineering, Faculty of Mining and Petroleum Engineering, \\ Institut Teknologi Bandung, Indonesia. Tel: 62-812-960-95629. E-mail: nitamusu@gmail.com
}

Received: December 14, 2017

Accepted: December 24, 2017 Online Published: December 23, 2017

doi:10.5539/mas.v12n1p51

URL: https://doi.org/10.5539/mas.v12n1p51

\begin{abstract}
Understanding geological features with engineering aspect has been done by previous studies and remains attractive by both geologists and engineers. This study employed data of a total of one hundred and seventy-nine (179) sandstone samples obtained from the Middle Miocene to Late Miocene Balikpapan Formation in Kutai Basin, Indonesia. The data includes thin section porosity, scanning electron microscope (SEM), $x$-ray diffraction (XRD), and capillary pressure $(\mathrm{Pc})$. All samples are mainly dominated by quartz with additional rock fragment and feldspar, and additional component such as plagioclase, heavy minerals, occasional carbonaceous materials, micas and opaque minerals. Detrital clays, pseudomatrix and laminated clays occurred locally in minor quantity. Porosity ranges from 6 to $28.8 .9 \%$, whereas permeability ranging from 0.02 and $4,718 \mathrm{mD}$. This study investigates the relationship of microscopic geological features with pore geometry and pore structures. Kozeny equation and Leverette's J-Function are implemented to characterize the pore geometry and structure in correlation with microscopic geologic features. The main findings of the study are that: $i$ ) combination of quartz content, texture, clay content, and the diagenetic history of quartz cementation strongly relates to both pore geometry and structure of the sandstone samples, $i i)$ the content of cements does not show a systematic effect on either pore geometry or pore structure, and iii) in general, for all the sandstone samples employed here, the higher quartz and lower clay contents tend to give both a larger pore geometry and lower pore structure in terms of pore tortuosity.
\end{abstract}

Keywords: pore geometry, pore structure, sandstone, Kozeny's equation, J-Function, microscopic geological features

\section{Introduction}

The main issues in rock typing of a sandstone is to link the geological processes forming the sandstone pore architecture - pore geometry and pore structure - with petrophysical properties. Understanding the pore geometry and pore structure is critical when dealing with rock heterogeneity. Sandstone heterogeneity is strongly affected by depositional environment and diagenetic processes that govern the rock texture such as grain size, grain shape or roundness, interconnectivity among pores, grain contact and sortation, and mineral composition including clay content and their mode of occurrences, consecutively affects the shape, size and pores interconnectivity.

Previous research on carbonate rocks was conducted by Gomes et al., (2008) in an attempt to understand the original facies, depositional environments and the diagenetic events affecting the original textures. They also looked at the connection between rocks and fluids with purpose to recognize the connection among lithofacies, petrophysical groups, and rock type. Leverette (1941) introduced J-Function to group capillary pressure data sets. Eventually, El Khatib (1995) showed mathematicaly that rock pore tortuosity was inversely related to Leverett JFunction. This relation can be interpreted as an indication of similarity in pore tortuosity for a number of rock samples with capillary pressure data sets that can be represented by a single J-Function curve. Archie (1950) who firstly introduced the term of rock type cited by other researchers (Gunter et. al., 1997, Guo et. al., 2005, Gomes et. al., 2008, Rushing et. al., 2008, Permadi \& Susilo, 2009, and Wibowo \& Permadi, 2013) defined that a rock type as a formation, which was deposited under similar condition and went through similar diagenesis, gave a specific porosity-permeability relationship with a particular group of capillary pressure curves and water 
saturation for a given height above a free water in reservoirs. Amaefule et. al., (1993) developed an identification technique and rock characterization by hydraulic flow units (HFU) concept based on pore-throat geometry. Their concept is to group rock samples on the basis of similarity in pore attribute so called as Flow Zone Indicator (FZI). Later, Wibowo \& Permadi (2013) developed a type curve for rock typing carbonates based on the relationship between pore geometry and pore structure. Therefore, our study focuses on the application of similar techniques on rock typing of sandstone reservoir.

Specifically for sandstones, there is still lack of research done for elaborating the physical meaning of J-Function and its relation to Archie's definition of rock type. The purpose of the present study is to investigate microscopic geologic factors that may control pore geometry and pore structure of sandstones. To facilitate the work, the data sets employed include routine core analysis (RCA), thin section, SEM, XRD, and capillary pressure ( $\mathrm{Pc}$ ) data. The goal of this study is to investigate the relation between geological aspects and engineering aspects because in practice these two aspects should synchronize each other.

\section{Method and Data}

\subsection{Pore Geometry and Pore Structure}

The approach used in this study follows the previous ones (Permadi \& Wibowo, 2013; Wibowo \& Permadi, 2013). Basically, hydraulic radius $m$ of a porous medium is defined as the ratio of pore volume $V_{p}$ to surface area of the pore space $S$ - where $m$ has unit of a length, and permeability has a unit of square of a length, the permeability can be written as follows (Scheidegger, 1960).

$$
k=K_{K} \times \frac{m^{2}}{f(\phi)}
$$

where $K_{K}=1 /\left(F_{S} \times \tau\right)$ which is the Kozeny constant (Harmsen, 1955), $F_{s}$ is shape factor, and $\tau$ is tortuosity. For cylindrical tubes, $\mathrm{f}(\phi)=1 / \phi$.

Substituting $m$ with $V_{p} / S$ into Eq. (1) and multiplying by $V_{b} / V_{b}$, where $V_{b}$ is bulk volume, yields the wellknown Kozeny equation:

$$
k=\frac{\phi^{3}}{\left(\tau F_{s} S_{b}{ }^{2}\right)}
$$

where $S_{b}$ is specific surface area with respect to bulk volume. Eq. (2) can be re-written as:

$$
\frac{k}{\phi^{3}}=\frac{1}{\left(\tau F_{S} S_{b}^{2}\right)}
$$

or

$$
\left(\frac{k}{\phi}\right)^{0.5}=\frac{\phi}{\left(\tau F_{S} S_{b}^{2}\right)^{0.5}}
$$

The term $(k / \phi)^{0.5}$ is denoted as pore geometry, or called as "mean hydraulic radius", whereas $\left(k / \phi^{3}\right)$ is designated as "pore structure" which explains all features of the internal structure of the pores Eq. (4). Eventually the relationship between pore geometry and pore structure is given as follows:

$$
\left(\frac{k}{\phi}\right)^{0.5}=\phi \times\left(\frac{k}{\phi^{3}}\right)^{0.5}
$$

or

$$
\left(\frac{k}{\phi}\right)^{0.5}=\left(\frac{V_{p}}{V_{b}}\right) \times\left(\frac{k}{\phi^{3}}\right)^{0.5}
$$

Now, Eq. (6) states that plotting $(k / \phi)^{0.5}$ as the dependent variable against $\left(k / \phi^{3}\right)$ as the independent variable on a log-log graph would yield a straight line with a positive slope of 0.5 and $V_{p} / V_{b}=1$. This is the consequence of the fact that Kozeny equation was derived by treating a porous medium as a bundle of smooth, tortuous capillary tubes with infinitely thin wall thickness. Moreover, the term $(k / \phi)^{0.5}$ in the equations above implies that the medium is treated as a single smooth capillary tube having $\phi$ or $V_{p} / V_{b}=1$. Such situation provides the fluid flowing with a flow efficiency of 1 , meaning that no delay of the fluid flow occurs at any point within the medium. Therefore, Eq. (6) represents an ideal model of porous media having very simple pore geometry and structure. 
When dealing with real porous rocks, the presence of micro, meso, and macro pores, pore contraction, pore divergence, dead ends, and pore wall roughness make the fluid flow far from the ideal situation (Wyllie \& Gardner, 1958). In a real and complex situation,velocity of the flowing fluid may significantly vary from one pore location to another and even flow stagnation occurs at the dead ends if any. In other words, the volume of flowing fluid per time unit differs from one position to another. It is therefore expected that the flow efficiency would be less than 1. To keep Eq. (5) applicable for real porous rocks, this equation can be modified to have the following general form:

$$
\left(\frac{k}{\phi}\right)^{0.5}=a\left(\frac{k}{\phi^{3}}\right)^{b}
$$

Eq. (7) is a power law equation that may represent the behavior of the nature (Peitgen et.al., 2004) and in fact the rocks under this study are a part of the nature. As described above, the constant $a$ may indicate flow efficiency and the exponent $b$ may represent pores complexity (Permadi \& Wibowo, 2013). However, according to the theory of similarity (Peitgen et al., 2004), $b$ is the so-called exponent of self-similarity. Further, it was mathematically shown by El Khatib (1995) that

$$
\tau=\frac{1}{2} \int_{0}^{1} \frac{d S_{w}}{J^{2}\left(S_{w}\right)}
$$

where $J(S w)$ is the capillary J-Function, defined as a function of water saturation $S_{w}$ (Leverett, 1941) as follows.

$$
J(S w)=\frac{P c(S w)}{\sigma \times \cos \theta} \times\left(\frac{k}{\phi}\right)^{0,5}
$$

In Eq. 9, $P_{c}$ is capillary pressure $(\mathrm{Pa}), k$ is permeability $\left(\mathrm{m}^{2}\right), \phi$ is porosity (fraction), $\sigma$ is interfacial tension $(\mathrm{Nm})$, $\theta$ is contact angle (degree). Then, by observing Eq. (3) and Eq. (7) and giving a value for $\tau F_{s},(k / \phi)^{0.5}$ is a function of only $1 / S_{b}$. For this situation, with respect to characteristisc of length, $1 / S_{b}$ is the scale of length for $(k / \phi)^{0.5}$. Since $b$ is an exponent of self-similarity for the variable of pore structure (see Eq. (7)), $b$ should then relate to similarity in tortuosity and thus in J-Function. This is why Leverett (1941) used $(k / \phi)^{0.5}$ to normalize capillary pressure data in the form of J-Function.

The description above concludes that a number of capillary data sets, that can be confined to become a single JFunction curve, should be sourced from rock samples having similar tortuosity (and probably similar pore shape factor $F_{s}$ as well, combined as a Kozeny constant, $\tau F_{s}$, defined in Eq. (1). The only difference among the samples is their values of $S_{b}$, specific internal surface area, for which the higher $(k / \phi)^{0.5}$, the lower $S_{b}$. Furthermore, application of Eq. (7) for these rock samples would say that all the rock samples would have at least the same value of $b$. Thus, the use of Eq. (6) is similar to that of J-Function for the purpose of rock grouping. Later, the results of this study will show the matches between these two methods in rock grouping or typing the sandstones.

\subsection{Data and Integrated Thin Section Petrography and SEM Description}

A total of one hundred and seventy-nine (179) sandstone data sets including RCA, thin section, SEM, XRD, and Pc data are available for this study. The sandstone samples were obtained from the main productive reservoir of the Middle Miocene to Late Miocene Balikpapan Formation of the Kutai Basin deposited on the deltaic plaindeltaic front environments. Balikpapan Formation is dominated by fine to coarse grained sandstone, dispersed claystone, shale, and coal. All samples are composed of mainly quartz. The porosity and permeability range from 6 to $28.8 .9 \%$ and 0.02 and $4718 \mathrm{mD}$, respectively.

The rock texture is described on the basis of the thin section petrography and SEM data analysis. The texture includes grains shape, grain size, sorting, and grain contact. Grain sizes are generally fine to medium sand with minor very fine sand and bimodal size of fine and medium sand. According to Powers (1953), grain roundness for the samples varies from angular to rounded with sub-angular to sub-rounded as the main types. Some sub-angular grains are quartz grains with overgrowths. Sortation of the samples is mostly moderate to well-sorted. The samples show variety of grain contact, mainly point and planar contacts with lesser floating, concave-convex, and suture contacts.

The composition of the framework grains is generally quartz-rich with additional rock fragments and feldspar with minor components including plagioclase, heavy minerals, occasionally carbonaceous materials, micas and opaque minerals. Detrital clays, pseudomatrix and laminated clays occurred locally in minor quantity. Detrital clay matrix is absent in samples from the lower interval, but is present in minor amount in samples from the upper interval. Pseudomatrix and laminated clays are commonly occurred. Identification of the samples made on present 
mineralogy according to Folk and Dott classifications (Folk, 1980 and Dott, 1964) provides information that the formation under this study covers sublitharenite followed by litharenite, quartzarenite, subarkose, lithic greywacke, and feldspathic litharenite.

Diagenetic events affecting sandstone reservoirs of the Balikpapan Formation include compaction, cementation, replacement or alteration, and dissolution. Most of the diagenetic events, except the dissolution, have reduced the porosity and permeability. The important factors controlling the porosity and permeability are compaction and cementation. The extent of compaction and cementation also depends on the grain size (Sculz-Rojahn \& Phillips, 1989, Rezaee \& Lemon, 1996) and sorting, and sediment framework.

\section{Results and Discussion}

\subsection{Grouping the Rock Samples by Using J-Function}

A total of 39 capillary pressure data sets available were transformed to J-Function using Eq. (9) above.

After plotting J-Function against water saturation $S_{w}$ (see Figure 1a), identification of the microscopic geological features is made by integrating the thin section petrography, SEM and XRD data for each corresponding rock sample for the purpose of J-Function grouping on the basis of similarity in the microscopic features. This procedure results in grouping the data points of J-Function and as exhibited in Figure 1b, indicating nine groups or rock types that can be formed from the SCAL data only. The physical meaning of J-Function curves in this figure is that, according to Eq. (8), pore tortuosity gets higher as the curve moves toward to the right.

A picture of the thin section of each rock type is also presented in this figure, while the corresponding description is given in Tables 1a and 1b. The rock type No. 1 is divided into two groups: RT-1a and RT-1b. The reason for this division is that although RT-1a and RT-1b show a very close rock type line but they have a different J-Function which is supported by microscopic geological features. In general, RT-1a also has a slightly coarser grain compared to RT-1b. The most distinct features that can be identified among the goups are due to differences in rock fabric or texture, specifically grain size and sorting, the comparison between quartz as brittle component and clay as ductile component, and importantly diagenesis. The red line in Figure $1 \mathrm{~b}$ shows in general the main causes of rock grouping. This implies that the similarity in pore structure or pore tortuosity for a group of rocks is controlled by similar both rock fabric or texture and results of diagenetic processes. All the data analyzed so far suggest that there is a certain relationship between J-Function and microscopic geological features. For particular sandstones used in this study, we found that some data sets sourced from different depositional environments or lithofacies can be parts of the same rock group (Gomes et.al., 2008; Permadi \& Susilo, 2009). This situation may exist when the original fabric or texture and probably the composition as well had been overprinted by diagenetic processes (Musu, 2000; Gomes et.al., 2008). Therefore, such a phenomenon should make no confusion in implementing JFunction in a reservoir with various facies because geologists and engineers deal with the present day results of diagenesis.
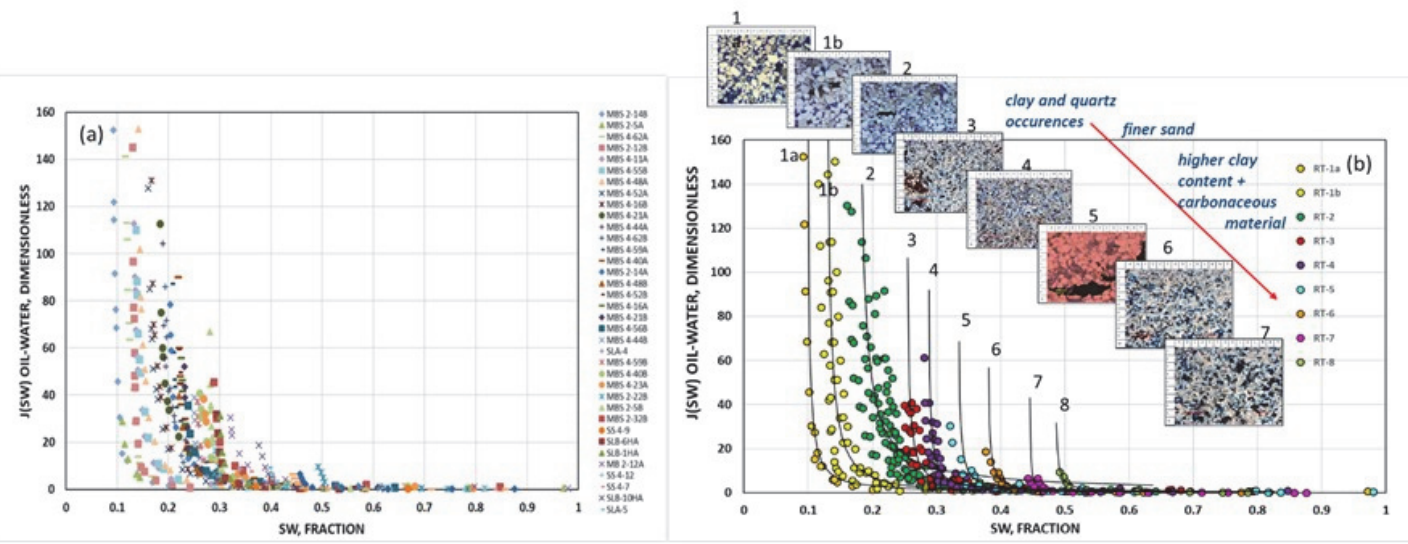

Figure 1a. Rock grouping by applying J-Function. The J-Function data before grouping (a) and after grouping

\subsection{Connectivity of Pore Geometry and Structure to Microscopic Geological Features}

The determination of pore geometry variable $(k / \phi)^{0.5}$ and pore structure variable $\left(k / \phi^{3}\right)$ for Eq. (7) requires RCA data. The RCA data of rock samples used for SCAL are separated in order to be recognized in rock grouping 
or typing. The purpose of separation is to identify the rock type for each SCAL sample. After determining the values of those two variables for both all the RCA and SCAL samples, plotting $(k / \phi)^{0.5}$ against $\left(k / \phi^{3}\right)$ on a $\log -\log$ graph was carried out. The identification of microscopic features for each sample of the corresponding data point was made to group the data points that have similar features; fifteen groups were finally obtained. A best trend line was then imposed on each group as exhibited in Figure 2, and the line may be called as a rock type line. The picture of a typical thin section with its description representing each of the rock types is presented in Tables 1a and 1b. As shown in Figure 2, there are three data points, the lowest ones assigned as rock type No's. 12,13 , and 14, that have no trend line made due to limited data available. In addition, the supporting microscopic geological data for these three rock samples are quite different from one to another, particularly in the texture and cement composition (see Table 2b). In regards with the trend lines constructed for the first twelve rock types (RT1a to RT-11), the equation of each rock type, which is referred to as a rock type equation, is presented in Table 2, showing that both of the exponent and the constant values systematically decrease with increasing rock type number. As expected, the exponent, which is b in Eq. (7), ranges from 0.431 down to 0.312 (all is smaller than 0.5). Meanwhile, the constant, which is a in Eq. (7), ranges from 0.628 down to 0.276 (all is lower than 1). The important point drawn from these results is that a given rock group is characterized by a power law equation with certain values for the exponent $b$ and the constant $a$.

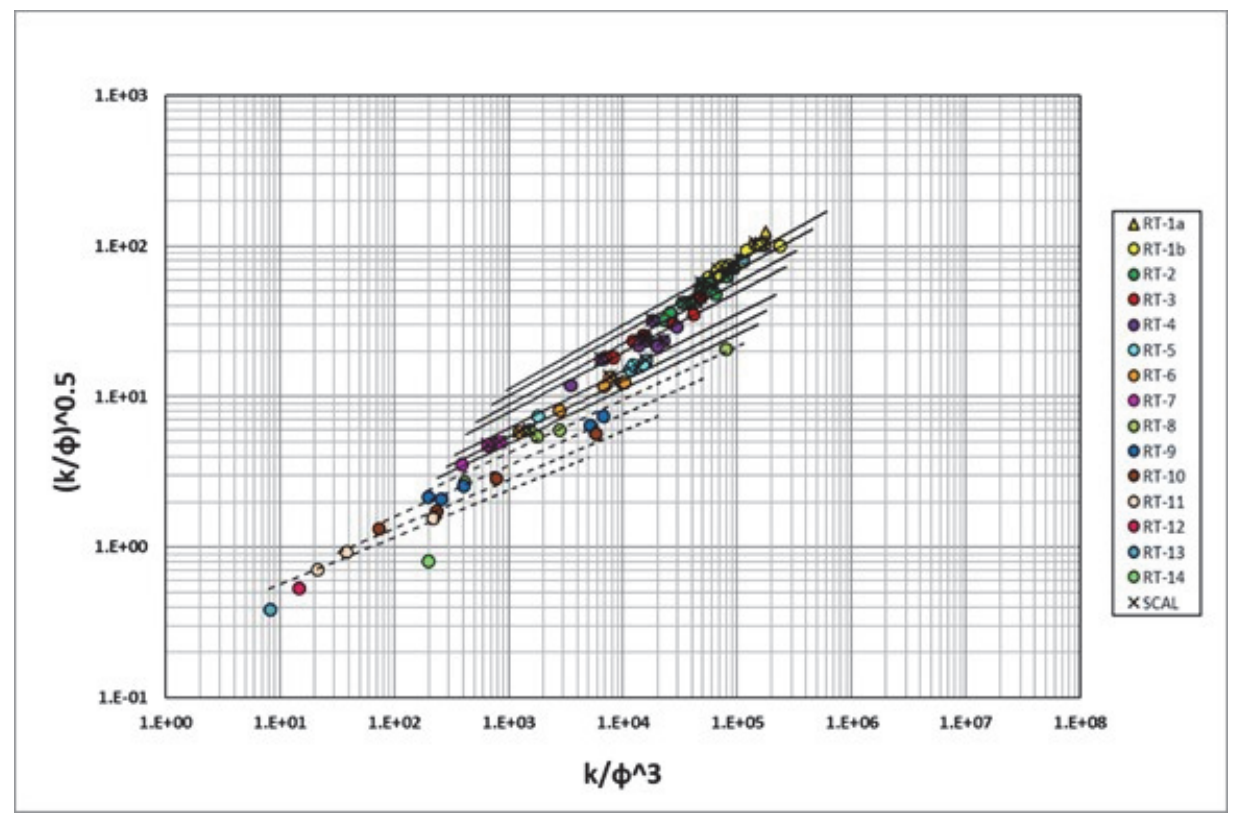

Figure 2. Rock grouping for the sanstones by using pore geometry - pore structure relation

For the case of the SCAL samples employed in this study, the data points of $(k / \phi)^{0.5}$ and the corresponding $\left(k / \phi^{3}\right)$ are also plotted using a black cross symbol in Figure 2. As Figure 2 shows, the SCAL data points spread over eight rock types: one point on rock type No. 1a (RT-1a), five points on RT-1b, seven points on RT-2, two points on RT-3, four points on RT-4, two points on RT-5, two points on RT-6, two points on RT-7, and one point on RT-8. This distribution is exactly the same as those resulted from the use of J-Function. The integrated thin section petrography, SEM, and XRD data were used to understand the relationship between microscopic geological features including mineralogy composition, texture and diagenesis and both pore geometry and structure. The microscopic features for the first nine rock groups (RT-1a to RT-8) are already presented in Table 1a, while for the rest, i.e. RT-9 to RT-14, are exhibited in Table 1 b. Based on the identification of the data, the microscopic features of the rock types for the sandstones are mainly determined by a combination of texture, mineralogy composition, and diagenesis. The rock types with very good to excellent permeability and porosity are in general the sandstones with larger grains, well-sorted, and dominated with higher quartz and lesser clay contents (Figure 1b). However, the available data of grain sizes for all the rock types (see Figure 3) demonstrate that grain size and grain sorting do not systematically define the division of rock groups. In other words, two or more rock groups may have about the same range of grain sizes. However, this is not a firm conclusion because, unfortunately, no supporting data of frequency distribution of the grain sizes is available for the present work. Despite grain sizes, there should be other geological features that may be systematically involved in the development of pore geometry and pore structure as discussed below. 
Table 1a. Microscopic geological features of RT-1a to RT-8 samples

\begin{tabular}{|c|c|c|c|c|c|c|}
\hline \multirow{2}{*}{$\begin{array}{l}\text { Rock } \\
\text { Type }\end{array}$} & \multirow{2}{*}{ Mirroscapic gealogical features } & \multicolumn{2}{|c|}{$k(\pi D)$} & \multicolumn{2}{|c|}{$\varphi$ (fract.) } & \multirow[b]{2}{*}{ Thin Sectian } \\
\hline & & Min & Max & $\mathrm{Min}$ & Max & \\
\hline $1 \mathrm{a}$ & 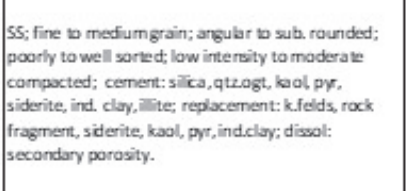 & 2952 & 4718 & 0.276 & 0.298 & 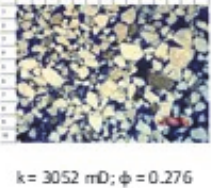 \\
\hline $1 b$ & 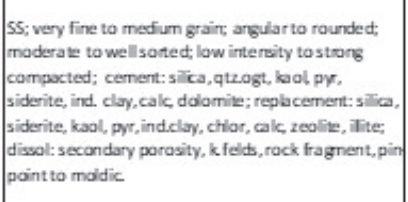 & 940.8 & 2644 & 0.210 & 0.273 & $\begin{array}{l}3,3 \\
k=2163 \mathrm{mD} ; \phi=0.209\end{array}$ \\
\hline 2 & 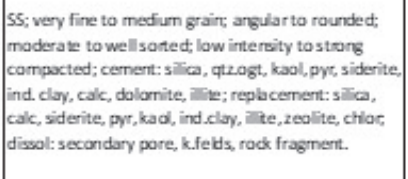 & 228.3 & 1230 & 0.189 & 0.259 & 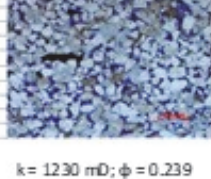 \\
\hline 3 & 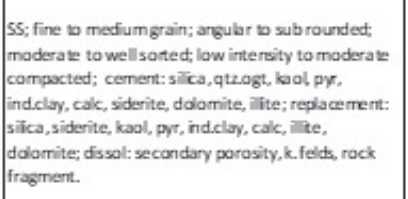 & 68.05 & 451 & 0.173 & 0.220 & 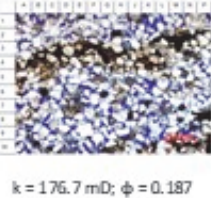 \\
\hline 4 & 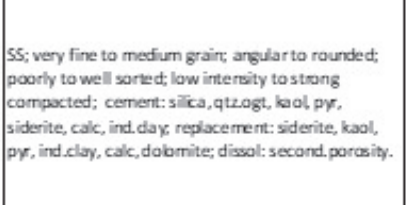 & 28.88 & 245.9 & 0.155 & 0.239 & 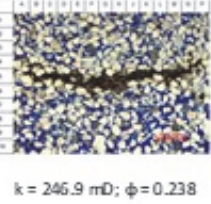 \\
\hline 5 & 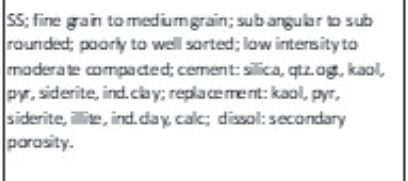 & 9.987 & 43 & 0.135 & 0.177 & $k=34 \pi D ; \phi=0.136$ \\
\hline 6 & 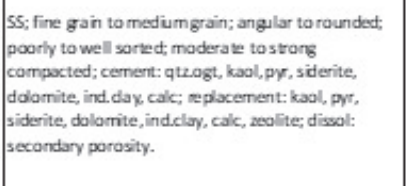 & 5.53 & 34.32 & 0.123 & 0.184 & 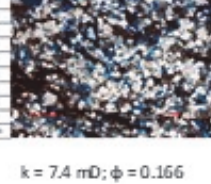 \\
\hline 7 & 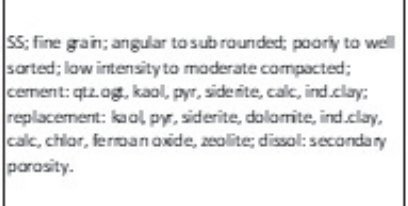 & 3.18 & 5.8 & 0.173 & 0.188 & 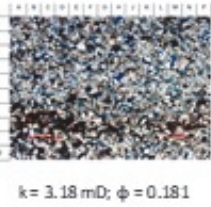 \\
\hline 8 & 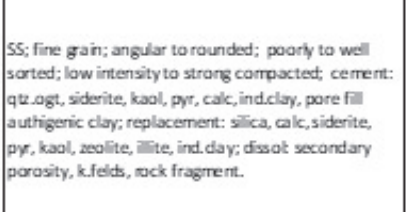 & 1006 & 31.89 & 0.074 & 0.154 & 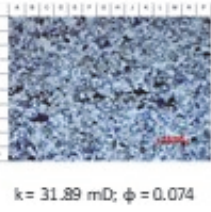 \\
\hline
\end{tabular}


Table 1b. Microscopic geological features of RT-9 to RT-14 samples

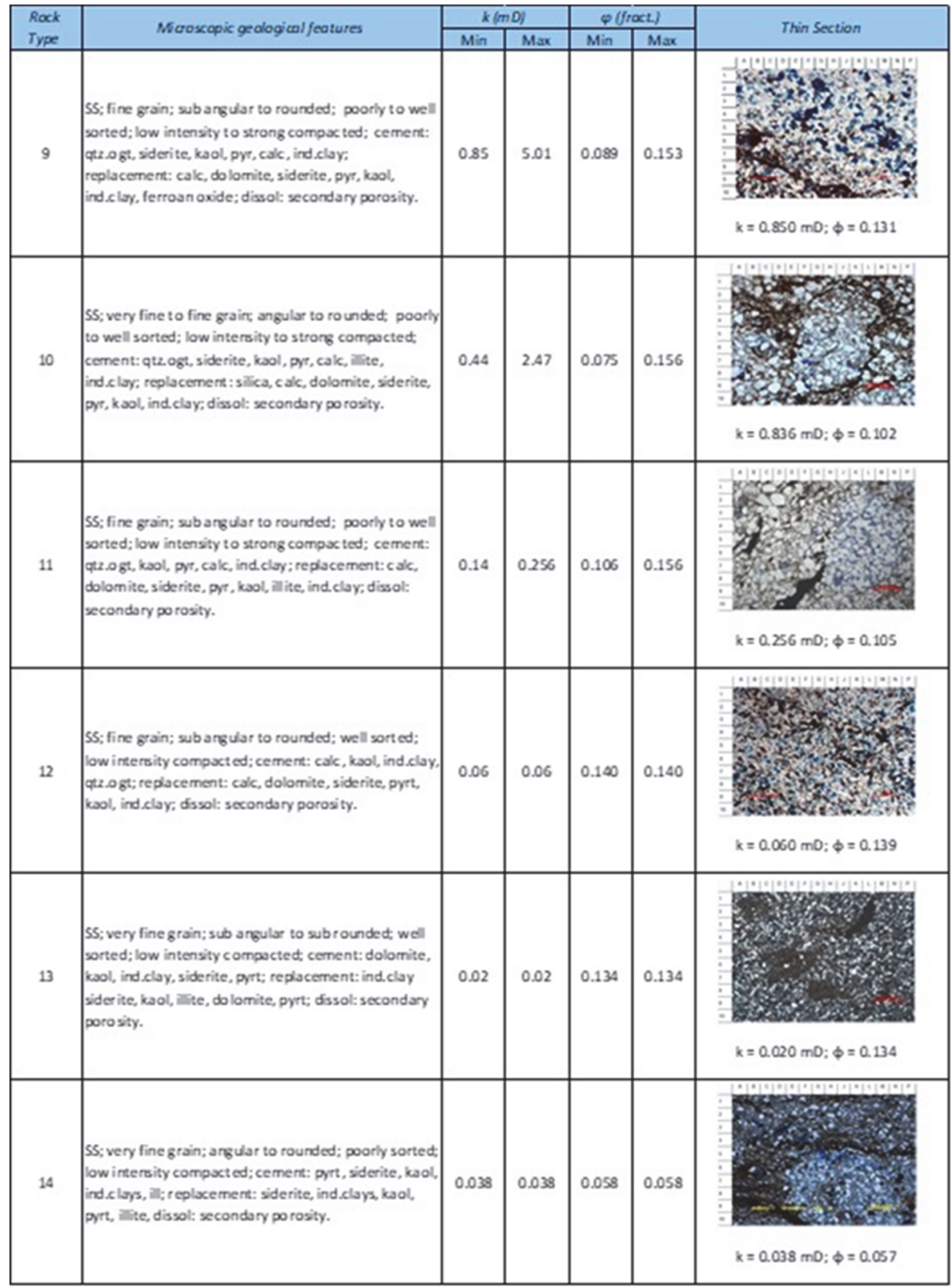

Figure 4 shows a finer grained-sandstone with lesser quartz and higher clay contents is belong to a rock type (RT3 ) with better quality in terms of permeability and porosity values as compared to coarser grain sandstone with a higher quartz content with lesser clay (RT-4). For this case, the rock sample of RT-3 had experienced early stage of quartz cementation that protected the sandstone from further compaction and contains clay distributed locally. On the contrary, the sample of RT-4 had been subjected to late quartz cementation, resulting in reduction of both porosity and pore throats, hence permeability, and the clay fills the pores. Schulz-Rojahn \& Phillips (1989) and Rezaee (1996) in their studies using cathodoluminescence (CL) discovered that quartz cementation might be preservational and (or) destructive with regards to porosity and reservoir quality as well. From the perspective of pore structure, however, observing Figure $1 \mathrm{~b}$ indicates that the pore tortuosity for RT-3 would be somewhat smaller than that for RT-4 according to the mathematical relation of tortuosity to J-Function (El Khatib, 1995). This situation for the sample of RT-3 would provide a fluid to flow easier when compared with that for the sample of RT-4. In fact, the corresponding data (see Figure 4) say that permeability of the RT-3 sample is $135 \mathrm{mD}$ with porosity of 0.198 , while those are $89 \mathrm{mD}$ and 0.158 for the RT-4 sample. All these values yield $(k / \phi)^{0.5}$ is equal to 26.1 and 23.7 for the samples of RT-3 and RT-4, respectively, demonstrating that the pore geometry of the RT3 sample is relatively larger than that of the RT-4 sample. This evaluation suggests that pore geometry and pore 
structure are appreciably controlled by diagenesis and mode of clay occurrences, not quartz and clay contents.

Table 2. Regression equation of each rock group for the sandstones of Balikpapan Formation

\begin{tabular}{cl}
\hline Rock Type & Regression Equation \\
\hline $1 \mathrm{a}$ & $(k / \phi)^{0.5}=0.628 k /\left(\phi^{3}\right)^{0.431}$ \\
$1 \mathrm{~b}$ & $(k / \phi)^{0.5}=0.599 k /\left(\phi^{3}\right)^{0.424}$ \\
2 & $(k / \phi)^{0.5}=0.569 k /\left(\phi^{3}\right)^{0.417}$ \\
3 & $(k / \phi)^{0.5}=0.531 k /\left(\phi^{3}\right)^{0.407}$ \\
4 & $(k / \phi)^{0.5}=0.502 k /\left(\phi^{3}\right)^{0.398}$ \\
5 & $(k / \phi)^{0.5}=0.443 k /\left(\phi^{3}\right)^{0.380}$ \\
6 & $(k / \phi)^{0.5}=0.416 k /\left(\phi^{3}\right)^{0.371}$ \\
7 & $(k / \phi)^{0.5}=0.394 k /\left(\phi^{3}\right)^{0.363}$ \\
8 & $(k / \phi)^{0.5}=0.367 k /\left(\phi^{3}\right)^{0.353}$ \\
9 & $(k / \phi)^{0.5}=0.334 k /\left(\phi^{3}\right)^{0.339}$ \\
10 & $(k / \phi)^{0.5}=0.299 k /\left(\phi^{3}\right)^{0.324}$ \\
11 & $(k / \phi)^{0.5}=0.276 k /\left(\phi^{3}\right)^{0.312}$ \\
12 & \\
13 & - \\
14 & - \\
\hline
\end{tabular}
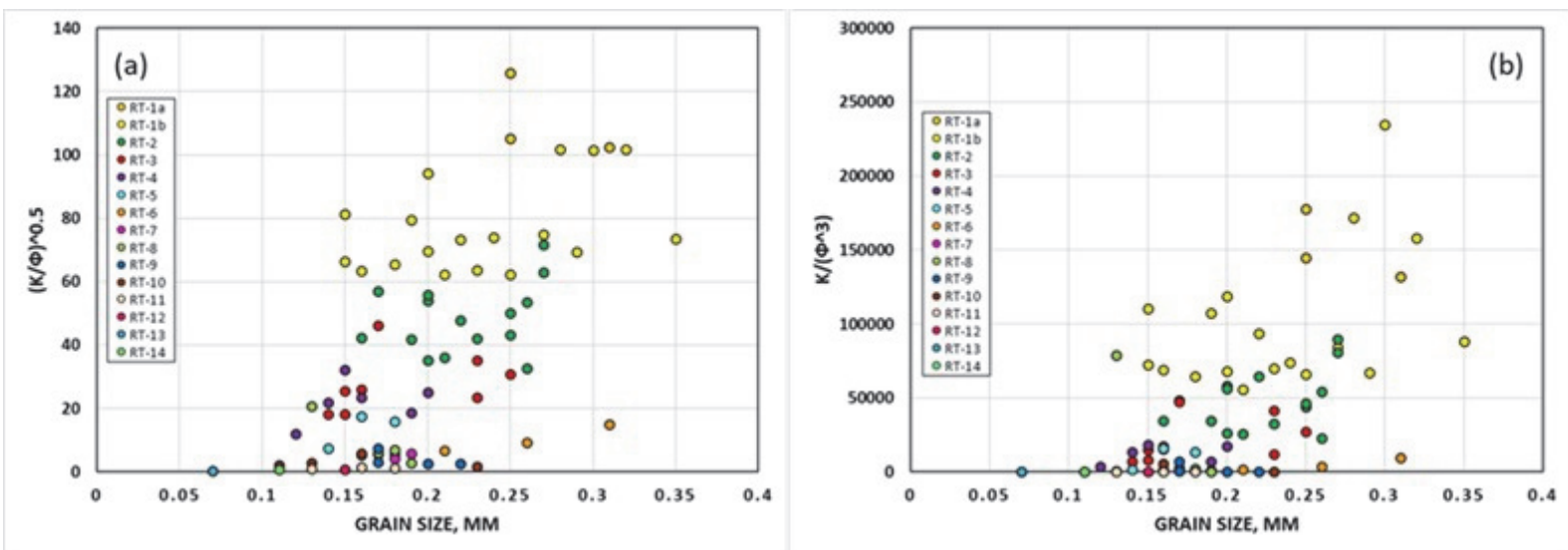

Figure 3. Relation between grain size and pore geometry (a) and pore structure (b) for all the rock types

When one follows a common believe, reservoir rock quality is determined by quartz and clay contents. The sandstones used that are grouped into rock types are still in parallel to this believe in that better quality rock types are those with a higher quartz content and a lesser clay percentage (see Figure 5). However, as rock quality can be inferred from the values of pore geometry and pore structure variables, it is interesting when one looks at the relationship between these pore attributes and both quartz and clay contents as exhibited in Figures 6 and 7 . Regardless of rock types, although the trendlines shown in these figures provide what one expects, there is a wide range of values of, for instance, pore geometry variable, particularly for quartz and clay contents within a relatively narrow range of 80 to $95 \%$ and 3 to $12 \%$, respectively. This wide range of pore geometry variable is mainly due to differences in the degree of quartz compaction, the time of diagenesis, and the mode of clay occurences. Previous studies have also investigated such factors (Schulz-Rojahn \& Phillips, 1989, Rezaee, 1996, and Musu, 2000). These would result in dividing the sandstones into several rock types, each has its own pore structure manifested in a certain J-Function curve or pore tortuosity as explained above. For a lower quartz content, a higher clay one, different rock texture, and different diagenetic event, the pore structure becomes even more complex and thus has 
higher pore tortuosity.

By observing further, a specific rock type, RT-1 or RT-2 for instance, the range of $(k / \phi)^{0.5}$ is a quite wide. Since a given rock type has a specific single J-Function curve and thus a certain pore tortuosity, again as described in section 2.1 above, the difference among the rock samples within the same rock type is due to different specific internal surface area $S_{b}$ for which a higher $(k / \phi)^{0.5}$ represents a lower $S_{b}$. Interestingly, it is found that $S_{b}$ is not always directly related to grain size. For example, two sample members of RT-1b have significant difference in $(k / \phi)^{0.5}$ values, 98.4 and 66.9 . The higher value comes from sample with mean grain size of 0.22 mm, whereas the lower one belongs to that with mean grain size of $0.35 \mathrm{~mm}$. The microscopic features data indicate that the former sample is characterized by domination of grain-point contact with additional floating and long contact, whereas the latter one has dominant long point contact type with addditional point and concave-convex contact types. This evaluation demonstrates that a given rock type may consist of rock parts with a wide variety of pore geometry but has a single J-Function. Observation of Figure 1b again indicates that variation of the minimum water saturation of each rock group or type is relatively small. In other words, for a given rock type, a wide variation of pore geometry could establish a small variation in connate water saturation.

\section{GEOLOGICAL MICROSCOPIC CHARACTERISTICS IN KUTEI BASIN}
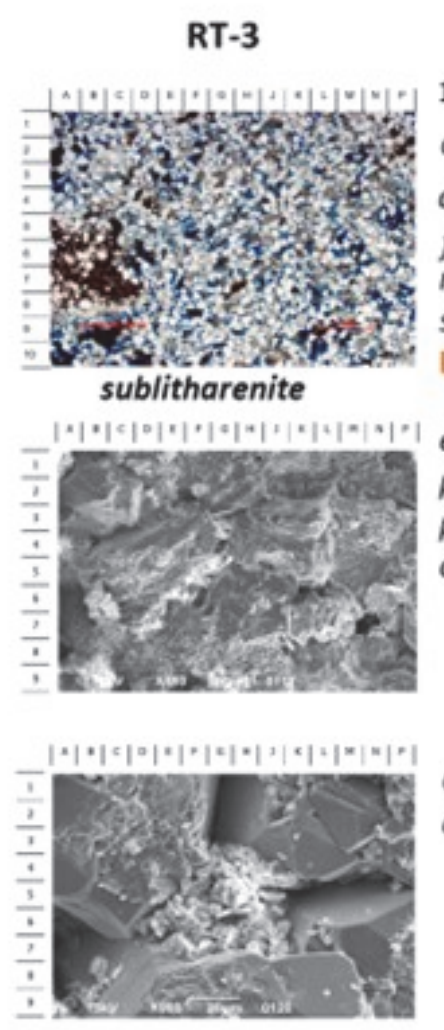

$135 \mathrm{md} / 19.84 \%$

quartz $47 \%$

clay $23.75 \%$

fine sand

moderately.

sorted

$1 \mathrm{C}>\mathrm{PC} \gg \mathrm{CC}$

early quartz cementation

preserving the pores and

pore-throats from further compaction

late quartz cementation reducing pores and pore-throats

\section{Clay occurs mostly as}

claystone and local lenses

\section{Clay occurs mostly filling} pores reducing pores

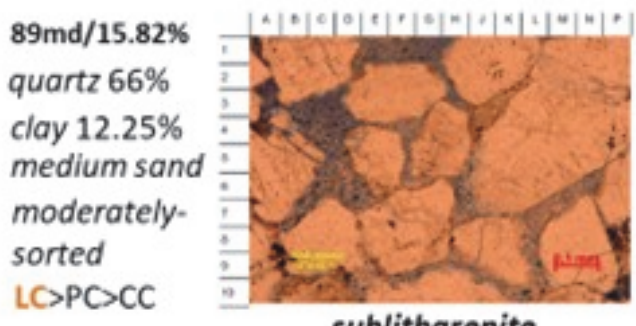

sublitharenite
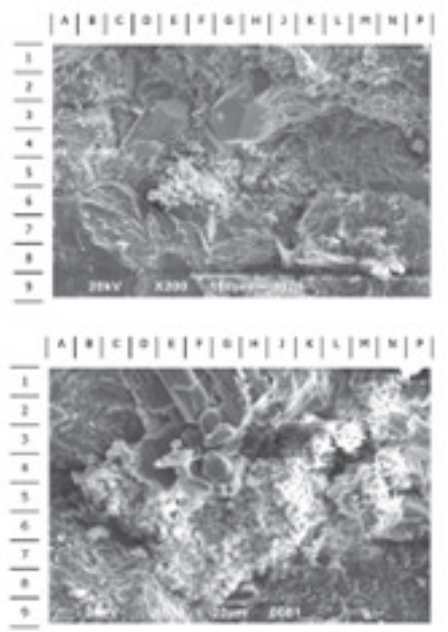

Figure 4. Typical texture of RT-3 and RT-4, showing the effects of cementation events and the mode of occurrences of clay minerals on the quality of rock types

Finally, the last factor that might influence pore geometry and structure is the amount of cementing agents including kaolinite, quartz overgrowths, dolomite, siderite, calcite, pyrite and indeterminate clay which mainly is illite with minor smectite and chlorite. For all the rock types, Figure 8 shows that the percentage of cements in the rocks has no clear effect on both pore geometry and structure. The various type of cement such as quartz overgrowths, early quartz cement development or late quartz cementation, and clay cement which has also variety of occurrences such as dispersed within pore spaces, pore-bridging or pore-lining would have discrete effect on both pore geometry and structure. Pore-lining, pore bridging, pore-filling cement reduces pore space and throats in some extent. The occurrence of clay cement also inhibits the precipitation of other cement especially quartz overgrowths (Thomson, 1979 and Bjorlykke, 1987), or clay cement such as kaolinite may also intergrown with 
quartz overgrowths. The existence of clay cement needs to be considered, although other diagenetic events such as grain dissolution and compaction may counteract the effect of cementation on pore geometry or pore structure. Therefore, the effect of cementation on pore geometry and pore structure gives scattered result as in Figure 8 .

Figure 9 shows RT-1a has relatively lower cement content comparing to RT-1b. However, if the cement is counted as individual such as quartz overgrowth, RT-1a has lesser or slightly higher quartz overgrowth than RT-1b(a) and RT-1b(b) respectively. It is believed that quartz overgrowth in RT-1a was a product of early stage quartz cementation, whereas quartz overgrowth in RT-1b (b) was from late stage quartz cementation. The timing of quartz cementation during diagenetic sequences influences the reservoir quality in terms of porosity and permeability (Rezaee, 1996, Musu, 2000, and Musu \& Widarsono, 2007). The quartz cement development in RT-1a and RT-1b (a) has been inhibited by the precipitation of other impurities such as kaolinite or illite, or quartz cement also intergrown with kaolinite (Bjorlykke, 1987). On the other hand, quartz overgrowth continued to develop in late diagenesis event as in RT-1b (b). Grain alteration is higher in RT-1a as it has lower cement than RT-1b. Other diagenetic events such as alteration of the unstable grains such as feldspar to kaolinite, or unstable grain dissolution forming secondary porosity, and compaction have lessened the effect of cementation towards pore geometry and pore structure.

It is obvious, however, rock types composed of finer grains and that had experienced further compaction have smaller values of both $(k / \phi)^{0.5}$ and $\left(k / \phi^{3}\right)$. The presence of cement in such groups makes the pore size even smaller that resulted in lower $(k / \phi)^{0.5}$ and the pore structure became more complex as indicated by its J-Function curve, manifesting the pore tortuosity.

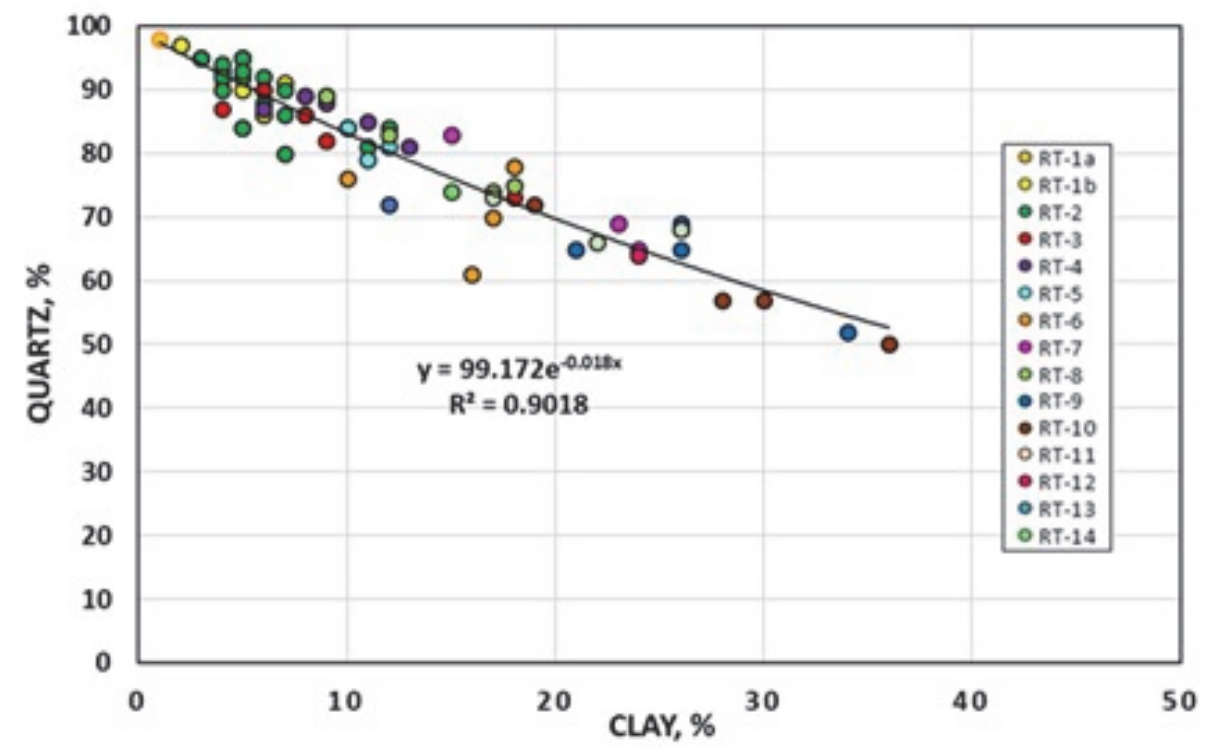

Figure 5. Relation between quartz content and total clay content for all the rock types
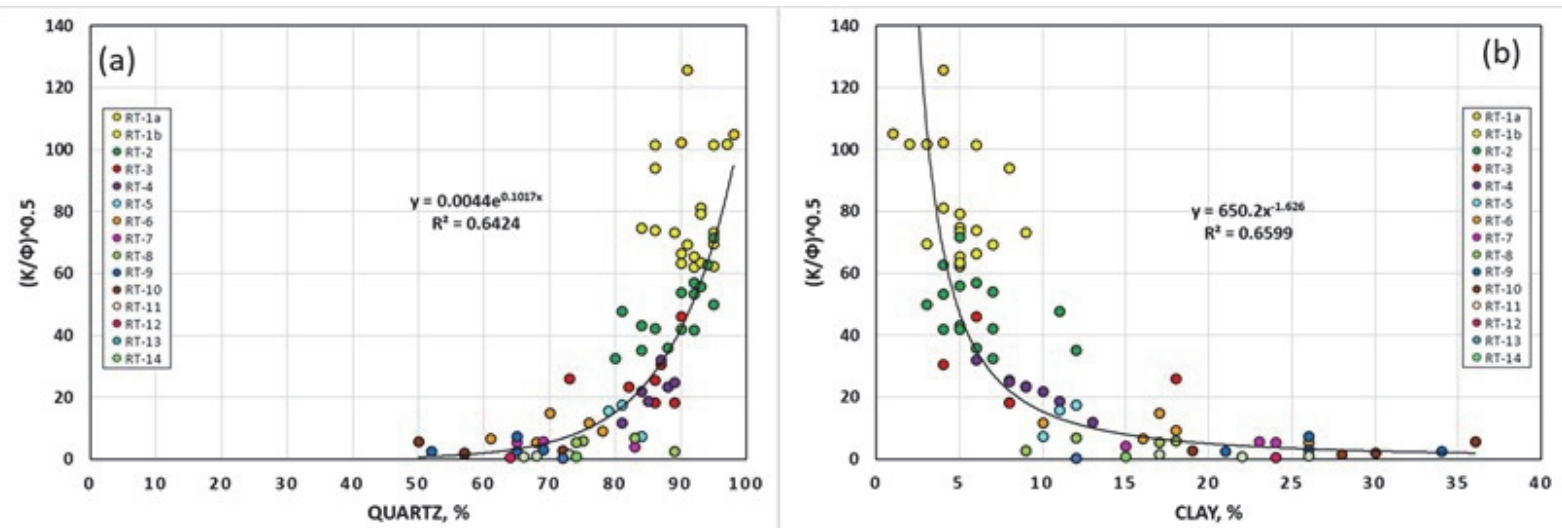

Figure 6. Relation between pore geometry and quartz content (a) and clay content (b) for all the rock types 

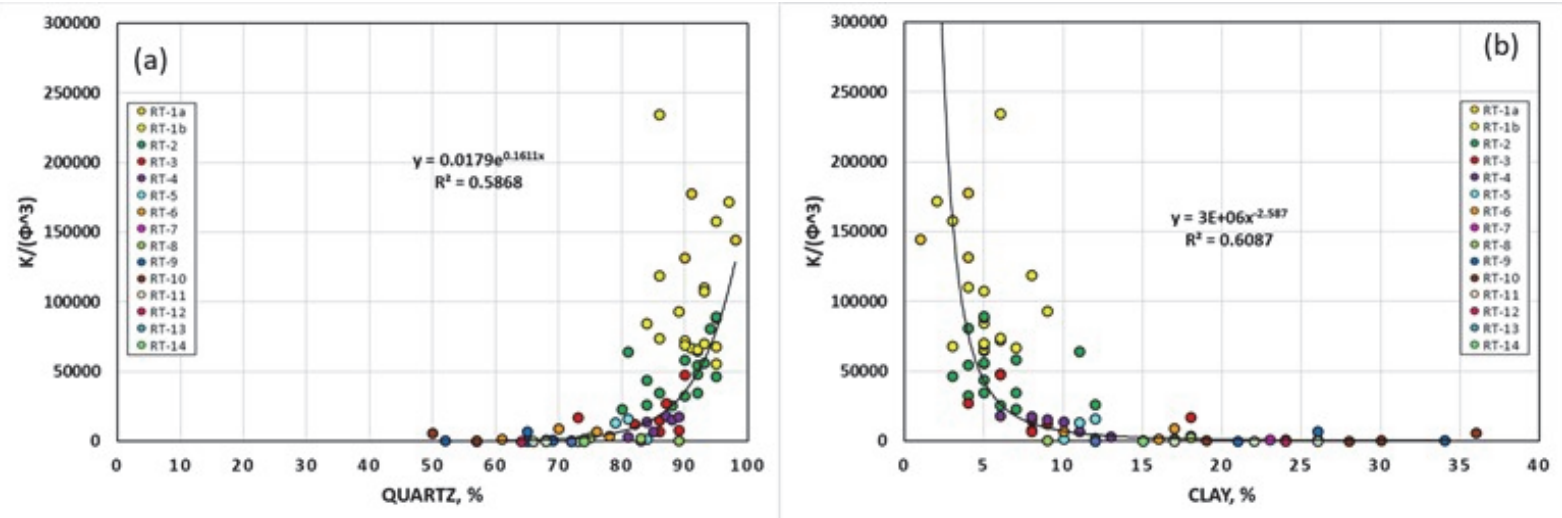

Figure 7. Relation between pore structure and quartz content (a) and clay content (b) for all the rock types
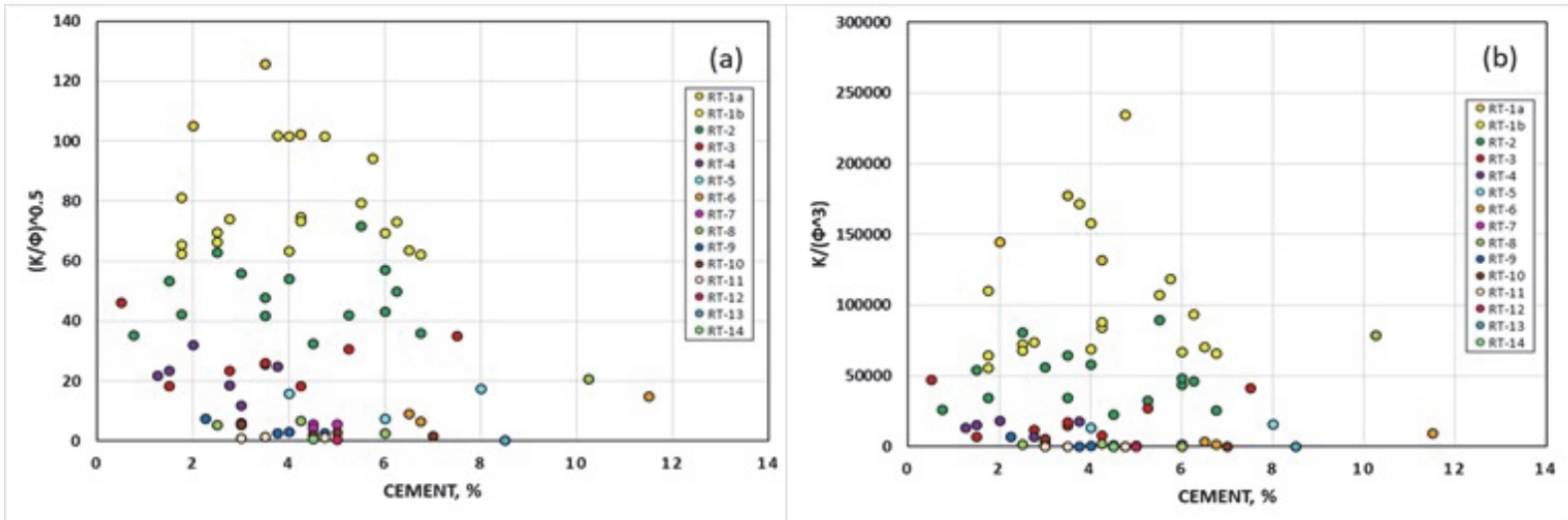

Figure 8. Relation between total cement and pore geometry (a) and pore structure (b) for all the rock types

\section{Conclusion}

In this study, the sandstone samples obtained from the Balikpapan Formation were employed to investigate the relation between microscopic geological features and both pore geometry and pore structure. A power law form of Kozeny equation and J-Function were used to characterize the geometry and structure of pore systems. In summary, the followings are withdrawn from the results:

1. It is found that both pore geometry and structure are in general controlled by quartz and clay contents. However, it is identified that the time and fashion of diagenesis such as early and late quartz cementation and degree of compaction play roles in determining the present day pore geometry and structure.

2. The finer the grain size and the higher clay content, the smaller the pore geometry and the larger the pore structure in terms of pore tortuosity as manifested by a J-Function with a higher connate water saturation.

3. No systematic effect of the amount of cements appears on both pore geometry and structure, before and after rock grouping or typing.

4. Overall, regardless of rock grouping, combination of texture, diagenesis, the mode of occurrences of the mineralogy especially clays, and mineralogy composition control both the pore geometry and pore structure of the sandstones. One of these features cannot stand alone as they all affecting one another. 


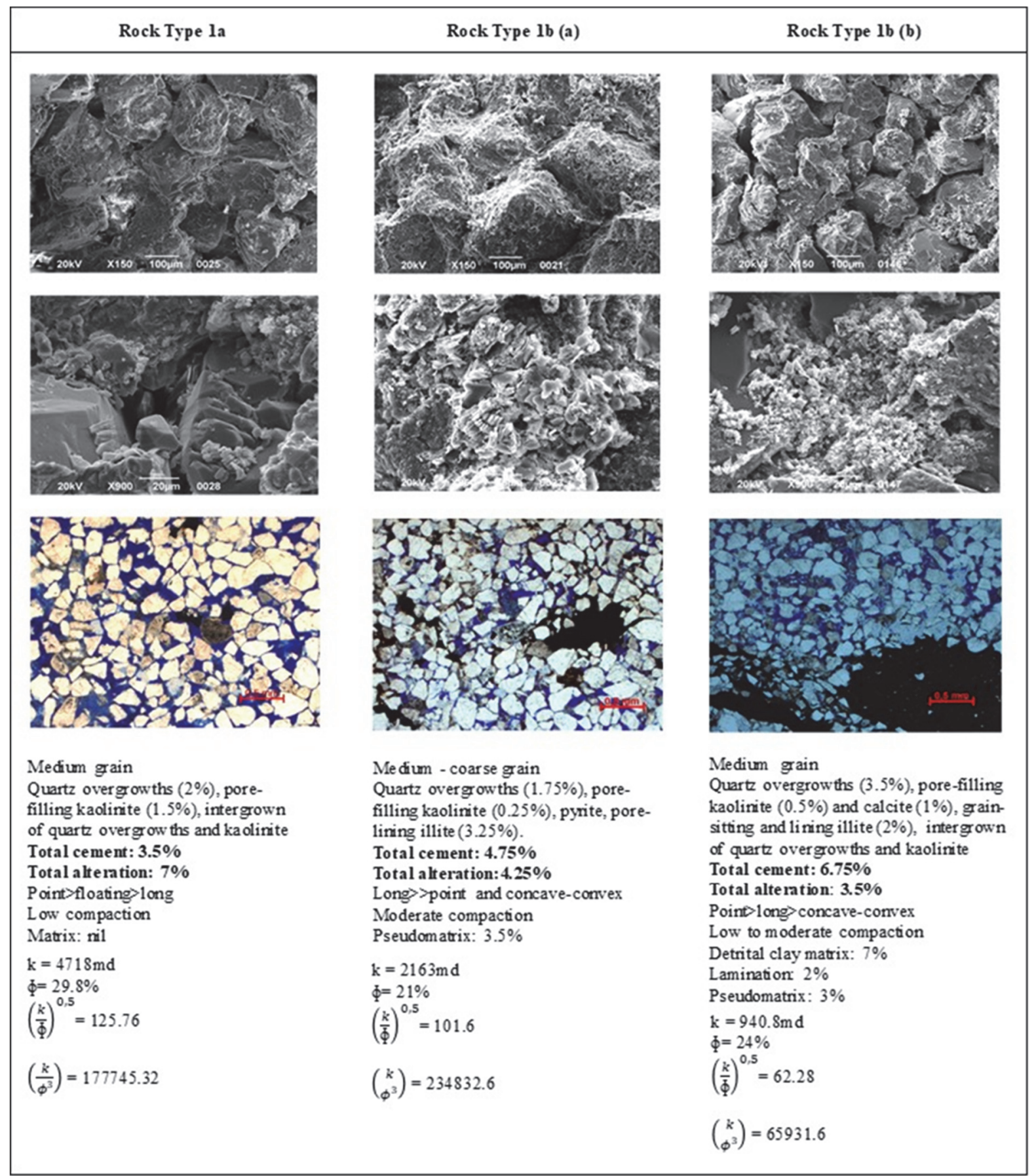

Figure 9. The variety of cements and their occurrences and their effects toward pore geometry and pore structure

\section{Acknowledgments}

One of the authors Junita Trivianty Musu would like to thank PPPTMGB "LEMIGAS" for supporting and giving her permission to enroll for doctoral program at Petroleum Engineering Study Program, Institut Teknologi Bandung, and for the core analysis data provided for her research.

\section{References}

Amaefule, J. O., Altunbay, M., Tiab, D., Kersey, D. G., \& Keelan, D. K. (1993, October). Enhanced reservoir description using core and log data to identify hydraulic (flow) units and predict permeability in uncored intervals/ wells. Paper SPE 26436 presented at the $68^{\text {th }}$ Annual Technical Conference and Exhibition of the SPE held in Houston, Texas. https://doi.org/10.2118/26436-MS 
Archie, G. E. (1950). Introduction to petrophysics of reservoir rocks. Bulletin of the American Association of Petroleum Geologists, 34(5), 943 - 961.

Bjorlykke, K. (1987). Formation of secondary porosity: How important is it? American Association of Petroleum Geologists Memoir, 37, 277-285.

Desouky, S. E. D. M. (2003). A new method for normalization of capillary pressure curves. Oil \& Gas Science and Technology - Rev. IFP, 58(5), 551-556. https://doi.org/10.2516/ogst:2003038

Dott, R. H. Jr. (1964). Wacke, graywacke and matrix - what approach to immature sandstone classification? Journal of Sedimentary Research, 34(3), 625-632. http://dx.doi.org/10.1306/09280707062

El-Khatib, N. (1995, March). Development of a modified capillary pressure-J Function. Paper SPE 29890 presented at the SPE Middle East Oil Show held in Bahrain. https://doi.org/10.2118/29890-MS

Folk, R. L. (1980). Petrology of Sedimentary Rocks. Hemphill Publishing Company, Austin, Texas. https://doi.org/10.1306/07300706146

Gomes, J. S., Ribeiro, M. T., Strohmenger, C. J., Negahban, S., \& Kalam, M. Z. (2006, November). Carbonate reservoir rock typing - Link between geology and SCAL. Paper SPE 118284 presented at the SPE Conference and Exhibition held in Abu Dhabi, UEA. https://doi.org/10.2118/118284-MS

Gunter, G. W., Finneran, J. M., Hartman, D. J., \& Miller, J. D. (1997, October). Early determination of reservoir flow units using an intergrated petrpohysical method. Paper SPE 38679 presented at the SPE Conference and Exhibition held in San Antonio, Texas. https://doi.org/10.2118/38679-MS

Guo, G., Diaz, M. A., Paz, F., \& Waninger, E. A. (2005, October). Rock typing as an effective tool for permeability and water-saturation modeling: A case study in a clastic reservoir in the Oriente Basin. Paper SPE 9703 presented at SPE Annual Technical Conference and Exhibition held in Dallas, Texas. https://doi.org/10.2118/97033-PA

Harmsen, G. J. (1955). The concept "hydraulic radius" in porous media. Petroleum Transactions. AIME, 204,274277.

Kozeny, J. (1927). Uber kapillare leitung des wassers im boden (Aufstieg versikerung und anwendung auf die bemasserung), sitzungsber akad, wiss, wein. Math-Naturwiss, KL 136(Ila), 271-306.

Leverett, M. C. (1941). Capillary behavior in porous solids. Trans. AIME, 142, 152-169. https://doi.org/10.2118/941152-G

Musu, J. T., \& Widarsono, B. (2007, November). Determination of NMR T2 cut off for ductile, low permeability shaly sandstone. Paper ASEG presented at ASEG 2007: 19th Geophysical Conference held in Perth. https://doi.org/10.1071/ASEG2007ab098

Musu, J. T., (2000). Relationship between Reservoir Properties and NMR Measurements: Examples from Tirrawarra Sandstone, Cooper Basin, South Australia. (Unpublished master's thesis). Adelaide University, Adelaide, Australia.

Peitgen, H. O., Jurgens, H., \& Saupe, D. (2004). Chaos and fractals: New frontiers of science. Springer Science. http://dx.doi.org/10.1007/b97624.

Permadi, P., \& Susilo, A. (2009, October). Permeability prediction and characteristics of pore structure and geometry as inferred from core data. Paper SPE 125350 presented at 2009 SPE/EAGE Reservoir Characterization and Simulation Conference held in Abu Dhabi. https://doi.org/10.2118/125350-MS

Permadi, P., \& Wibowo, A. S. (2013, September). Kozeny's equation for better core analysis. Paper SCA2013-048 presented at the the International Symposium of the Society of Core Analysis held in Napa Valley, California.

Powers, M. C. (1953). A new roundness scale for sedimentary particles. Journal of Sedimentary Petrology, 23, 117-119.

Rezaee, M. R. (1996). Reservoir Characterization of the Tirrawarra Sandstone in the Moorari and Fly Lake Brolga Fields, Southern Cooper Basin, South Australia (Unpublished doctoral dissertation). Adelaide University, Adelaide, Australia.

Rezaee, M. R., \& Lemon, N. M. (1996). Influence of depositional environment on diagenesis and reservoir quality: Tirrawarra Sandstone reservoir, Southern Cooper Basin. Australian Journal of Petroleum Geologist, 19(4), 369-391. https://doi.org/10.1111/j.1747-5457.1996.tb00445.x

Rushing, J. A., Newsham, K. E., \& Blasingame, T. A. (2008, February). Rock typing-keys to understanding 
productivity in tight gas sands. Paper SPE 114164 presented at SPE Unconventional Reservoirs Conference held in Keystone, Colorado. https://doi.org/10.2118/114164-MS

Scheidegger, A. E. (1959). The physics of flow through porous media. University of Toronto Press, Canada.

Schulz-Rojahn, J. P., \& Phillip, S. E. (1989). Diagenetic alteration of Permian reservoir sandstones in the Nappamerri Trough and adjacent areas, Southern Cooper Basin. In B.J. O’Neil (Ed.), The Cooper and Eromanga Basins Australia: Proceedings of the Cooper and Eromanga Basins Conference, Adelaide. Petroleum Exploration Society of Australia (pp. 629-645). Society of Petroleum Engineers and Australian Society of Exploration Geophysicists (South Australian Branches).

Thomson, A. (1979). Preservation of porosity in the Deep Woodbine/ Tuscaloosa Trend, Louisiana. Gulf Coast Assoc. Geol. Socs. Trans., 29, 396-403. https://doi.org/10.2118/10137-PA

Wibowo, A. S., \& Permadi, P. (2013). A type curve for carbonates rock typing. International Petroleum Technology Conference, 16663. https://doi.org/10.2523/IPTC-16663-MS

\section{Copyrights}

Copyright for this article is retained by the author(s), with first publication rights granted to the journal.

This is an open-access article distributed under the terms and conditions of the Creative Commons Attribution license (http://creativecommons.org/licenses/by/4.0/). 